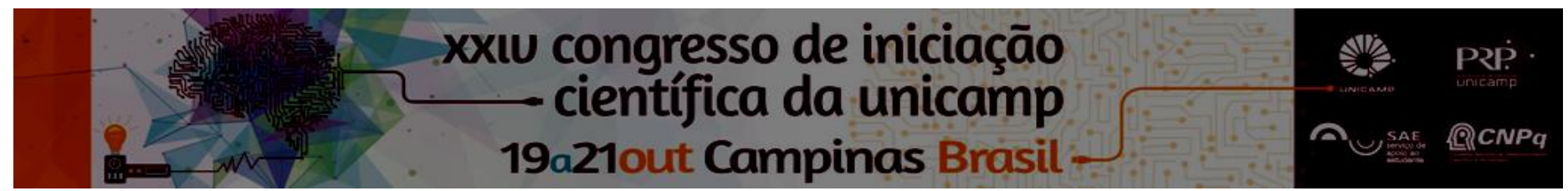

\title{
FAMILIAL HYPERCHOLESTEROLEMIA (FH) IN CHILDREN AND ADOLESCENTS: OPTIMIZATION OF DETECTION FOR EARLY TREATMENT.
}

\section{Guilherme Redezuk*,Erica I.L. Gomes,Thiago Quinaglia, Vanessa H. S. Zago, Flávia Silva Mothe,Leonardo Staffa, José Roberto Matos Souza, Andrei C. Sposito, Eliana Cotta de Faria.}

\begin{abstract}
The Familial Hypercholesterolemia ( $\mathrm{FH})$ is the most common co-autosomal dominant inherited condition in man. It is mainly caused by mutations in the following three genes: the encoding: the receiver of low-density lipoprotein LDL-C (most common), or apolipoprotein B100 proprotein convertase subutilisina / kexina type 9 (PCSK-9). The resulting chronic elevations in LDL-C levels entail the development of early atherosclerotic cardiovascular disease. The overall estimated prevalence for heterozygous HF ranges from about $1 / 200-2501 / 500$ and homozygous $\mathrm{FH}$ is 1/1 000000 . The childhood is the ideal period of life to discriminate between dyslipidemias FH and not FH. serum LDL-C $\geq 190 \mathrm{mg} / \mathrm{dL}$ (2 measures up to 3 months), or LDL-C $\geq 160 \mathrm{mg} / \mathrm{dL}$ with a family history of premature coronary disease or high levels of cholesterol increased basal in a parent or LDL $-C \geq 130 \mathrm{mg} / \mathrm{dL}$ with positive genetic diagnosis in families may be used as the phenotypic criteria for diagnosis. It is the aim of this study make the early diagnosis of HF in a population sample of children, adolescents and adults Brazilian city of Campinas / SP.

Key words: Familial Hypercholesterolemia, Dyslipidemia, Atherosclerosis.

\section{Introduction}

The Familial Hypercholesterolemia ( FH) as the most common autosomal condition in man, has its consequences present even in childhood, is indispensable, for the efficient management, early diagnosis of cases.

Consequences : chronic elevations in plasma levels of LDL- cholesterol.

- there were no statistical differences between sexes in the range of $1 \mathrm{~d}-19 y e a r s$, similar results are found in the literature

- after exclusion of secondary causes, the phenotypic diagnosis $\mathrm{FH}$ should be confirmed by genetic and treatment initiated
\end{abstract}

\section{Clinical manifestations of FH :}

- Early atherosclerotic cardiovascular disease.

- A - corneal bow ; B - tendon xanthoma
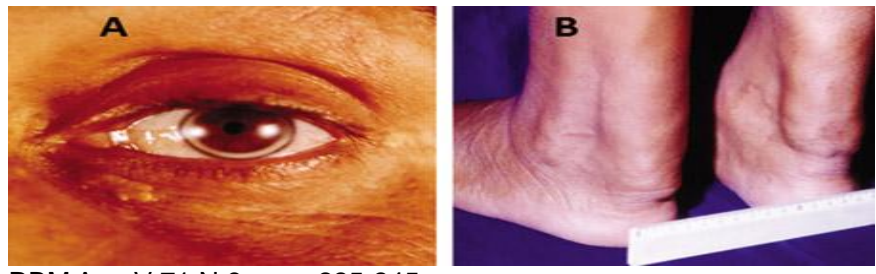

RBM Ago V 71 N 8, pgs.:225-245

Objectives: HF screening in a sample of children and adolescents for early diagnosis and treatment of HF.

\section{Results and Discussion}

Métodos: Laboratory results of serum analyzes LDL cholesterol by homogeneous method Direct (Roche ) done Were selected from consecutively. The sample was 472 050 individuals attended at all basic healthcare sistems of Campinas, SP, in the period 2008 to 2015 . We assessed the prevalence in the age range of specific subgroups (1 day to 19 years, 1 day to 1 year-364d, 2 to 11 years and 12 to 19 years). The criterion of LDL C $\geq 190 \mathrm{mg} / \mathrm{dL}$ was used for phenotypic screening, according to the I Brazilian Guidelines for Familial Hypercholesterolemia (FH).

- 382 suspected cases of HF (144 children / adolescents 221), prevalence of 0.003 , compared to the world of $\sim 0.002$

- $\quad$ higher prevalence in females, 12-19 years subgroup: likely resulting from secondary causes of not $\mathrm{FH}$ hypercholesterolemia

\section{Chart 1: Prevalence of FH suspects by sex and age}

\begin{tabular}{|c|c|c|c|c|}
\hline Groups $(d / y)^{*}$ & $\mathbf{N}$ & Prevalence** (\%) & $\mathrm{Cl} 95 \%$ & Frequencies $* * * *(\%)$ \\
\hline T 1d-19y $(\mathrm{N}=61267)$ & 382 & 0,62 & $0,56-0,69$ & - \\
\hline M 1d-19y (N=27102) & 140 & $0,52 * * *$ & $0,43-0,60$ & 0,23 \\
\hline F 1d-19ay(N=34165) & 242 & $0,71^{* * *}$ & $0,62-0,80$ & 0,39 \\
\hline T 1d-1y"(N=1017) & 33 & 3,24 & $2,14-4,35$ & 0,05 \\
\hline M 1d-1y" (N=390) & 8 & 2,05 & $0,64-3,46$ & 0,79 \\
\hline F 1d-1y"(N=627) & 25 & 3,99 & $2,46-5,52$ & 2,46 \\
\hline$T 2-11 y(N=21623)$ & 111 & 0,51 & $0,42-0,61$ & 0,18 \\
\hline M 2-11y (N=10458) & 51 & 0,49 & $0,35-0,52$ & 0,24 \\
\hline$F 2-11 y(N=11165)$ & 60 & 0,54 & $0,40-0,67$ & 0,28 \\
\hline T 12-19y(N=36062) & 221 & 0,61 & $0,53-0,69$ & 0,36 \\
\hline M 12-19y (N=15004) & 71 & $0,47 * * *$ & $0,36-0,58$ & 0,20 \\
\hline$F 12-19 y(N=21068)$ & 150 & $0,71 * * *$ & $0,60-0,83$ & 0,42 \\
\hline
\end{tabular}

${ }^{*} \mathrm{~d} / \mathrm{y}=$ days/years; $\mathrm{N}=$ with $\mathrm{LDL}-\mathrm{C} \geq 190 \mathrm{mg} / \mathrm{dL} ;{ }^{* * *}$ test chi-squared $=\mathrm{p} \leq$ 0,$05 ; " 1 d-1 y=1$ day a 1 year-364d ; $T=$ total; $M=$ male gender; $F=$ female gender $\mathrm{N}=$ number; $\mathrm{Cl}=$ mean confidence interval $(95 \%) ;{ }^{* \star \star *}$ calculated from the $\mathrm{nT}$

\section{Conclusions}

The results of this study point to the urgent need for continued $\mathrm{FH}$ screening in the population of children and adolescents for their early diagnosis and handling.

\section{Acknowledgements}

